\title{
Avances e implicaciones éticosociales de la nanomedicina: una revisión desde el caso del cáncer cerebral*
}

\author{
Gian Carlo Delgado Ramos** \\ Luis Alberto Hernández Burciaga***
}

RESUMEN: Entre las aplicaciones de la nanotecnología más prometedoras y dinámicas están aquellas del sector salud. Destacan las investigaciones en enfermedades como el cáncer, VIH sida, diabetes, osteoartritis, enfermedades degenerativas y desordenes cardiovasculares y nerviosos. El presente texto abre con una breve introducción acerca del estado actual de la investigación y desarrollo de la nanotecnología y sus aplicaciones médicas, particularmente desde una perspectiva económica. A continuación, indaga con mayor detenimiento el caso del cáncer y en específico del cáncer cerebral, los retos de su diagnóstico y tratamiento y el potencial de la nanotecnología para confrontarlos. A partir de una revisión de más de tres mil artículos registrados en PubMed se ofrece un análisis sobre el avance de la investigación en cáncer y cáncer cerebral en lo que va del siglo XXI, tanto en lo que se refiere al espectro de tipos de cáncer como de estructuras nanométricas empleadas. Se cierra con una reflexión tanto de los potenciales riesgos asociados a la exposición directa a nanomateriales, como de las implicaciones sociales y éticas del avance de la nanomedicina. Con la inclusión de una propuesta normativa de modelo integral de gestión y distribución del riesgo, se argumenta que es oportuno estimular y regular responsable y democráticamente al sector de la nanomedicina y en sí de las nanotecnologías como un todo a modo de minimizar eventuales costos y riesgos innecesarios. PALABRAS ClavE: nanomedicina, cáncer cerebral, aspectos sociales, ética, regulación.

ABSTRACT: Health applications are among the most promising and dynamic of nanotechnology innovation. To highlight are those focused on cancer, HIV-AIDS, diabetes, osteoarthritis, degenerative diseases, and cardiovascular and nervous disorders. This paper deals with nanoapplications for brain cancer. It starts with a brief introduction about current state of research and development of nanotechnology and its medical applications, particularly from an economic perspective. It then briefly presents cancer and brain cancer diseases, current challenges of diagnosis and treatment and nanotechnology potential to solve them. After a review of more than three thousand papers registered in PubMed database (from 2000 to 2013), an analysis of the progress of nanorelated research in cancer is offered. It includes a general description of types of cancers, including brain cancer, and nanostructures currently being studied. Finally, a reflection on potential risks associated with direct exposure to nanomaterials, as well as on social and ethical implications of the progress of nanomedicine is presented. By outlining a normative model of an integrated management and distribution of risk, we argue the relevance of democratically and responsibly promoting and regulating nanotechnology in general and nanomedicine in particular; all with the purpose of minimizing eventual costs and unnecessary risks.

KEYWORDS: nanomedicine, brain cancer, social aspects, ethical regulation.

\footnotetext{
* El presente trabajo es parte de los resultados de investigación del Laboratorio Socio-Económico en Nanociencia y Nanotecnología (LABnano), proyecto financiado por el Consejo Nacional de Ciencia y Tecnología (Conacyt), No. 118244.

** Investigador de tiempo completo, definitivo, del programa "El Mundo en el Siglo XXI" del Centro de Investigaciones Interdisciplinarias en Ciencias y Humanidades de la UNAM. Integrante del Sistema Nacional de Investigadores del Conacyt. Es coordinador de LABnano. Contacto: giandelgado@unam.mx

*** Pasante de la carrera de filosofía de la Facultad de Filosofía y Letras de la UNAM. Becario del proyecto LABnano.
} 


\section{INTRODUCCIÓN}

La nanociencia es el estudio de las características del mundo nanométrico, el de los átomos y las moléculas, una dimensión donde las propiedades de la materia cambian con respecto a las propiedades que suele presentar a la macroescala; desde el color, hasta la maleabilidad, resistencia, conductividad, etc. El diseño de materiales nanoestructurados para tales o cuales aplicaciones que demandan ciertas propiedades o características se denomina nanotecnología. El espectro de aplicación de tal frente tecnológico es en principio ilimitado pues a tal escala se abre la posibilidad de manipular, tanto materia orgánica como inorgánica. Las expectativas son mayores, al punto que incluso se cree que estamos ante la conformación de una nueva revolución industrial.

Tanto los gobiernos como el sector privado han destinado crecientes esfuerzos y recursos. Se verifica que el gasto público mundial en nanotecnología fue, en 1997, de 430 millones de dólares (mdd) pero para el 2003, poco después de que EUA y otros países lanzaran sus iniciativas gubernamentales para apoyar su desarrollo, el gasto aumentó a 3 mil mdd y desde entonces no ha dejado de crecer (Delgado, 2013). Al 2010, la suma global de financiamiento público a la nanotecnología rondaba los 70 mil millones de dólares, de los cuales 18 mil millones se ejercieron sólo en 2010(Roco, Chad y Hersam, 2010).

Por su parte, el mercado global de lo nano, estimado en 15,700 millones de dólares en 2010 y en 20,100 millones de dólares en 2011, se estima podría ubicarse en el rango de los 27 mil a 30 mil millones de dólares al año 2015 (Electronics, 2010; Global Industry Analysts, 2012; BCC Research, 2012-A). El ritmo de crecimiento entre 2013 y 2017 se calcula en 19\% (Research Markets, 2013). Otras estimaciones precisan que las ventas totales podrían sumar 48,900 millones en 2017 , de las cuales 37,300 millones corresponderían a nanomateriales y 11,400 millones de dólares a nanoherramientas (BCC Research, 2012-A).

De tomar en cuenta es que hoy, casi $20 \%$ del gasto en investigación se concentra en sector salud y ciencias de la vida, seguido del área de químicos, tecnologías de la información y comunicación, aplicaciones ambientales, energía y transporte (Nanospots, 2007).

\section{NANOMEDICINA, FRENTE TECNOCIENTÍFICO CON POTENCIAL ${ }^{1}$}

El uso de bionanoestructuras y nanodispositivos para sistemas y procedimientos mejorados y novedosos de prevención, diagnóstico, tratamiento y regeneración constituye el corazón de la denominada "nanomedicina", refiriendo precisamente al cruce de la nanotecnología y la medicina y que, hoy por hoy, en sí, alude esencialmente al encuentro de la nanotecnología y la biotecnología en el amplio ámbito de la salud, esta última con mayor tendencia hacia la denominada medicina personalizada.

El mercado global de la nanomedicina alcanzó 50 mil millones de dólares en 2011 y las perspectivas hablan que aumentará a más del doble para 2016, por ello, las pa-

\footnotetext{
Para una reflexión más amplia sobre el avance de la nanomedicina en países desarrollados y en desarrollo, así como de sus implicaciones, léase: Arnaldi et al., 2011.
} 
tentes en dicho rubro registran un aumento importante a nivel mundial en lo que va del siglo XXI. ${ }^{2}$ De un universo del negocio de la salud, estimado en alrededor del $15 \%$ del PIB de EUA y del 8\% del PIB de Europa o más de 5 billones de dólares por año, el negocio de la nanomedicina se calcula que crecerá, sólo en EUA, a un ritmo de 17\% anual, alcanzando un valor de 110 mil millones de dólares para el 2016 (Fredonia Group, 2007).

Sólo en lo que se refiere a nanopartículas para el desarrollo de agentes terapéuticos, el Observatorio Europeo de Ciencia y Tecnología identificaba ya desde 2006, más de 150 empresas involucradas en su desarrollo y unas tres docenas de compuestos aprobados para su comercialización con ventas en el rango de los 6,800 millones de dólares (Wagner y Zweck, 2006). De notarse es que el grueso de las ventas se relacionaban en $75 \%$, al mercado de aplicaciones de entrega "inteligente" de droga (Ibid.). ${ }^{3}$ Se trata de un negocio que es la mitad del existente en EUA, país que, en general, aún domina la innovación y mercado de la salud (NSF, 2010). ${ }^{4}$

Algunas estimaciones para el negocio de sistemas de entrega de droga que utilizan nanotecnología calculan ventas por 4,800 millones de dólares para el 2012 en un mercado total en ese rubro de 67 mil millones de dólares (NanotechNow, sin fecha). Incluso se llega a considerar que el mercado nano en tal rubro podría ser de hasta 14 mil millones de dólares para el 2015 (Jain y Jain, 2006). En lo que respecta a la participación de la nanotecnología en productos para atender enfermedades del sistema nervioso central, se estima que el mercado fue, en 2011, de 14 mil millones de dólares con expectativas de duplicarse en 2016 (BCC Research, 2012-B). El mercado de nanoproductos para diagnóstico y terapia de cáncer (en sus distintas tipologías) es igualmente atractivo pues en 2011 se valoró en 5,500 millones y se espera llegue a 12,700 millones de dólares para el 2016 (Ibid.). Asimismo, el mercado de nanomateriales en el segmento de medicina personal, en especial la denominada medicina teranostica (fusión de diagnóstico y terapia), se estima en 187 mil millones para el 2017 (BCC Research, 2013).

El creciente uso de nanomateriales en innovaciones médicas, hoy por hoy ya en al menos medio centenar de productos, el grueso no disponibles para consumo directo sino más bien empleados por investigadores o profesionistas especializados, corrobora tales expectativas (véanse ejemplos de productos en la tabla 1). No obstante, en efecto, el mayor potencial está a penas en pleno desarrollo, por ello se habla de cuatro etapas o generaciones de la nanotecnología; la última alcanzando su despegue entre

\footnotetext{
2 Wagner y Zweck (2006) argumentan que en la Oficina Europea de Patentes se registraron en 2003 unas dos mil patentes en nanomedicina de unas 220 en 1993. Según la base de datos de la Oficina Europea de Patentes, de 1993 a 2003, el 59\% de las patentes estaban relacionadas con la entrega de droga, el 14\% a diagnósticos in vitro, $13 \%$ a generación de imágenes y $8 \%$ a biomateriales <www.observatorionano.eu>.

3 Diagnósticos in vitro el $11 \%$, biomateriales $6 \%$, generación de imagen $4 \%$, drogas y terapias $2 \%$, implantes activos 1\%. Lideran en publicaciones en el área: EUA con 32\%, Japón con 9\%, Alemania con 8\%, Reino Unido con 7\% y Francia con 6\% (Wagner y Zweck, 2006: 1213).

4 En 2007, EUA publicó la mitad de los artículos relacionados con la biomedicina y ciencias de la vida del mundo. Para ese mismo año, EUA se adjudicaba el $32 \%$ del mercado mundial del sector, seguido de lejos por Europa (NSF, 2010). En el caso puntual de la nanomedicina, se calcula que domina la tercera parte de las publicaciones, la mitad de las solicitudes de patentes y la tercera parte de las patentes otorgadas. Con base en: Wagner y Zweck, 2006; Maclurcan, 2005. En lo que respecta a la porción del mercado estadounidense para productos médicos con algún tipo de innovación "nano", se calcula que ésa podría llegar a los 100 mil millones de dólares para el 2016 (Bawa y Johnson, 2007: 882).
} 
TABLA 1. Ejemplos de productos nanodesarrollados para el sector médico

\begin{tabular}{|c|c|c|}
\hline Área de aplicación & Productos & Empresa o entidad desarrolladora \\
\hline \multirow[t]{3}{*}{ Cáncer } & Abrazane & American pharmaceutical partners (EUA) \\
\hline & Xoxil & ALZA Corporation (EUA) \\
\hline & Emend & Merck and Co. (EUA) \\
\hline \multirow[t]{2}{*}{ Sustituto de hueso } & Vitoss & Orthovita (EUA) \\
\hline & Zirconium Oxide & Alatir Nanotechnologies (EUA) \\
\hline Colesterol & TriCor & Abbott Laboratories (EUA) \\
\hline \multirow[t]{2}{*}{ Diagnóstico } & $\begin{array}{l}\text { NanoChip Technology } \\
\text { Microarrays }\end{array}$ & CombiMatrix Corporation (EUA) \\
\hline & CellTracks & Immunicon Corporation (EUA) \\
\hline \multirow[t]{3}{*}{ Equipo médico } & TiMESH ( para laparoscopía) & GfE Medizintechnik GmbH (Alemania) \\
\hline & $\begin{array}{l}\text { EnSeal Sistema de Fusión de Vasos } \\
\text { para Laparoscopía }\end{array}$ & SurgRx (EUA) \\
\hline & Acticoat (vendaje antibacteriano) & Smith \& Nephew (EUA) \\
\hline \multirow[t]{2}{*}{ Imagenología } & Qdot nanocrystals & Invitrogen Corporation (EUA) \\
\hline & TriLite Technology & Crystalplex Corporation (EUA) \\
\hline Terapia hormonal & $\begin{array}{l}\text { Estrasorb } \\
\text { (entrega de estrógenos por } \\
\text { medio de nanoplataforma de } \\
\text { nanopartículas) }\end{array}$ & Novavax (EUA) \\
\hline Inmunosupresores & $\begin{array}{l}\text { Rapamune } \\
\text { (profilaxis pararechazo de órgano } \\
\text { en transplantes renales) }\end{array}$ & Wyeth (EUA) \\
\hline
\end{tabular}

Fuente: Con base en <www.nanotechproject.org/inventories/medicine/>.

el 2015 y el 2020. Tales etapas se centran en el desarrollo de: 1) nanoestructuras pasivas, 2) nanoestructuras activas, 3) sistemas de nanosistemas, y, 4) nanosistemas moleculares (Renn y Roco, 2006).

Por lo pronto, ya se explora el uso de nanocristales en el desarrollo de tecnología de formulación de drogas; el uso de compuestos inyectables que estimulen y soporten la regeneración de tejido mediante el crecimiento de moléculas que se autoensamblan en nanofibras; el empleo de puntos cuánticos para el análisis del funcionamiento y comportamiento de drogas; el desarrollo de estructuras útiles para transportar drogas que tiene como objeto atacar tumores cancerosos; el uso de fulerenos (C60) en el ataque del virus del VIH; el empleo de recubrimientos bactericidas para su aplicación en superficies de quirófanos que tienen contacto con el paciente para así evitar infecciones imprevistas; el empleo de los avances en la electroinformática, especialmente los que refieren a las aplicaciones de los laboratorios-en-un-chip con componentes nanométricos, para el diagnóstico o monitoreo de bajo costo y en tiempo real de ciertas enfermedades, deficiencias, etcétera. Otras aplicaciones refieren a la mejora del propio instrumental médico, del equipo de resolución molecular ultravanzada para la generación de nanoimágenes útiles para diagnósticos más precisos, procedimientos 
novedosos de diagnóstico in vivo e in vitro, uso de biosensores para diagnóstico, tratamiento y posterapia y la mejora de diversos dispositivos portátiles de diagnóstico o monitoreo, la encapsulación de droga y el desarrollo de procesos de entrega enfocada de drogas, tratamientos para la regeneración de tejidos, desde hueso, nervios, cartílago y piel, hasta tratamientos más sofisticados y que, junto con los anteriores, se les denomina medicina regenerativa. Esta última, posible gracias al desarrollo de biomateriales e implantes biológicoinertes, bioactivos o inteligentes y adaptativos -incluyendo implantes retinales, auditivos, de la espina dorsal y el cerebro- - Véanse en la tabla 2 ejemplos de pruebas clínicas de productos nano en EUA.

Considerando lo arriba descrito, la nanomedicina ha sido definida por la Fundación Europea para la Ciencia (ESF, por sus siglas en inglés) como: “...la ciencia y la tecnología de diagnóstico, tratamiento y prevención de enfermedades y lesiones trau-

TABLA 2. Ejemplos de pruebas clínicas en curso en EUA

\begin{tabular}{|c|c|c|}
\hline Nombre de la prueba & $\begin{array}{l}\text { Número de la prueba y } \\
\text { año de registro }\end{array}$ & Responsable \\
\hline $\begin{array}{l}\text { Estudio de prueba de concepto de crema de nanoe- } \\
\text { mulsión tópica para dolor de rodilla (osteoartritis) al } \\
3 \% \text { de diclofenaco }\end{array}$ & $\begin{array}{l}\text { NCT00484120 (2007) } \\
\text { 2DA FASE COMPLETA }\end{array}$ & Barzilai Medical Center (Israel) \\
\hline $\begin{array}{l}\text { Nanogeneradores atómicos dirigidos en pacientes con } \\
\text { lesiones malignas avanzadas de leucemia mieloides }\end{array}$ & $\begin{array}{l}\text { NCT00672165 (2008) } \\
\text { FASE } 1\end{array}$ & $\begin{array}{l}\text { Memorail Sloan-Kettering Cancer Center } \\
\text { National Cancer Institute } \\
\text { Actinium Pharmaceuticals }\end{array}$ \\
\hline $\begin{array}{l}\text { Evaluación clínica de restauraciones nanocerámicas } \\
\text { CAD/CAM }\end{array}$ & $\begin{array}{l}\text { NCT01464294 (2011) } \\
\text { FASE } 1\end{array}$ & $\begin{array}{l}\text { 3M (EUA) } \\
\text { Study by University of Michigan Dental } \\
\text { Clinics }\end{array}$ \\
\hline $\begin{array}{l}\text { Monitoreo biológico de nanopartículas en las vías res- } \\
\text { piratorias de niños asmáticos }\end{array}$ & $\begin{array}{l}\text { NCT01754948 (2012) } \\
\text { FASE } 1\end{array}$ & Tel -Aviv Sourasky Medical Center (Israel) \\
\hline $\begin{array}{l}\text { Perfil farmacoquinético y de seguridad de inyección de } \\
\text { concentrado de paclitaxel para nanodispersión sola y } \\
\text { en combinación con carboplatino en sujetos con tumo- } \\
\text { res sólidos avanzados }\end{array}$ & $\begin{array}{l}\text { NCT01304303 (2011) } \\
\text { FASE } 1\end{array}$ & $\begin{array}{l}\text { Sun Pharma Advanced Research Company } \\
\text { Studies by Roswell Park Cancer Institute }\end{array}$ \\
\hline $\begin{array}{l}\text { Nab-paclitaxel en cáncer de seno metastásico para pa- } \\
\text { cientes sin éxito al uso de solvente de taxano (Tiffany) }\end{array}$ & $\begin{array}{l}\text { NCT1416558 (2011) } \\
\text { FASE } 1\end{array}$ & German Breast Group \\
\hline $\begin{array}{l}\text { Detección temprana de cáncer de pulmón - nanoaná- } \\
\text { lisis por medio de exhalación respiratoria }\end{array}$ & $\begin{array}{l}\text { NCT01386203 (2011) } \\
\text { FASE } 1\end{array}$ & Sheba Medical Center \\
\hline $\begin{array}{l}\text { Evaluación in vivo de nanotoxicidad de biomaterial de } \\
\text { plata }\end{array}$ & NCT01243320 (2011) & $\begin{array}{l}\text { University of Utah } \\
\text { University of Utah Hosptal and Clinics }\end{array}$ \\
\hline $\begin{array}{l}\text { Terapia focal para cáncer de próstata localizado, usan- } \\
\text { do electroporación irreversible (nano). }\end{array}$ & $\begin{array}{l}\text { NCT01726894 (2012) } \\
\text { EN CURSO }\end{array}$ & $\begin{array}{l}\text { University College London Hospitals (Reino } \\
\text { Unido) }\end{array}$ \\
\hline $\begin{array}{l}\text { Terapia focal para cáncer de próstata localizado, usan- } \\
\text { do electroporación irreversible (nano). }\end{array}$ & $\begin{array}{l}\text { NCT01726894 (2012) } \\
\text { EN CURSO }\end{array}$ & $\begin{array}{l}\text { University College London Hospitals (Reino } \\
\text { Unido) }\end{array}$ \\
\hline $\begin{array}{l}\text { Estudio de PLX } 486 \text { como agente individual y con gem- } \\
\text { citabina plus Nab-paclitaxel en pacientes con tumores } \\
\text { sólidos avanzados }\end{array}$ & $\begin{array}{l}\text { NCT01804530 (2013) } \\
\text { FASE } 1\end{array}$ & $\begin{array}{l}\text { Traslational Genomics Research Institute, } \\
\text { University of California, Medical } \\
\text { University of South Carolina, Sarah } \\
\text { Cannon Research Institute, Plexxikon. }\end{array}$ \\
\hline
\end{tabular}

Fuente: Elaboración propia con información de la base de datos de clinicaltrials.gov. 
máticas, para aliviar el dolor, así como para preservar y mejorar la salud humana, utilizando herramientas moleculares y el conocimiento molecular del cuerpo humano." (ESF, 2005; Webster, 2005). Comprende, según dicha definición de la Fundación, “... cinco subdisciplinas, que en muchos modos se superponen y generan sinergias mutuas en las siguientes cuestiones: herramientas analíticas, nanoimagen, nanomateriales y nanodispositivos, nuevas terapias y sistemas de entrega de droga y aspectos regulatorios y toxicológicos" (ESF, 2005).

A lo dicho, súmese en tal contexto la implementación paralela de la e-medicine o la medicina que tiene como soporte la conformación de expedientes electrónicos cada vez más detallados de los pacientes. Y más aún, la integración del ya mencionado enfoque de la medicina personalizada, misma que requiere como punto de partida el seguimiento y actualización de descripciones detalladas de las variaciones biológicas de los pacientes en relación con diversos factores personales como lo son los contextos ambientales, sociales y los estilos de vida de cada individuo o grupo de individuos. Ello precisa la recolección de un gran portafolio de muestras que deben ser catalogadas, analizadas y guardadas en biobancos, cuestión que pone sobre la mesa nuevos retos técnicos y tecnológicos, ${ }^{5}$ pero también cuestiones sociales, legales y éticas.

De modo similar a la biotecnología, la nano(bio)medicina llega con la promesa y expectativas de curar enfermedades tales como el cáncer, VIH sida, diabetes, osteoartritis, enfermedades degenerativas (por ejemplo, Alzhéimer, Párkinson, esclerosis múltiple) y desordenes cardiovasculares y nerviosos. Propone revolucionar especialmente áreas como la oncología, cardiología, inmunología, neurología, endocrinología y microbiología, e inclusive otras como la odontología.

Los retos tecnocientíficos no son menores. Se identifica la necesidad de mejorar la biodistribución de las nanopartículas y las tecnologías de generación de imagen para visualizarlas; la optimización de la transportación de masa a través de compartimentos biológicos; la identificación de puntos de referencia para el desarrollo de nuevas clases de materiales; la necesidad de investigación en el desarrollo de toda una caja de herramientas analíticas para la manufactura nanofarmacéutica y el desarrollo de nuevos modelos para predecir parámetros de riesgo-beneficio (Sanhai et al., 2008). A ello, por supuesto, se suman cuestiones de efectos ambientales y preocupaciones toxicológicas, estandarización, regulación, consideraciones éticas, entre otras, como el acceso desigual a los beneficios desarrollados.

\section{NANOTECNOLOGÍA Y CÁNCER CEREBRAL}

El cáncer es ahora una de las cinco principales causas de defunción a nivel mundial. Se le atribuyen 7.9 millones de defunciones ocurridas en 2007. La Organización Mundial de la Salud (OMS), estima que alrededor de 84 millones de personas morirán a causa de esta enfermedad entre 2005 y 2015. En México, entre 1992 al 2001, la proporción de muertes por cáncer en México pasó de 0.6 a 13.1\% del total de defunciones ocurridas por todas las causas y en toda la población.

\footnotetext{
5 No sólo de bioinformática y bioestadística, sino de modelos de análisis, entre otras herramientas, que en efecto puedan hacer uso útil de la disponibilidad de creciente información pues ésta no se traduce automáticamente en capacidades de diagnóstico o prevención, por ejemplo.
} 
En particular, los tumores del sistema nervioso central (SNC), ya sean de alto o bajo grado de malignidad, constituyen un problema en el sistema de salud mundial, al punto que en ciertos países, como en México, llegan a ser una de las principales causas de mortalidad.

Existen más de 120 tipos diferentes de cáncer cerebral, siendo éste una de las enfermedades del cerebro entre otras de tipo degenerativo, infeccioso, vascular o traumático - las enfermedades degenerativas de mayor trascendencia a nivel mundial son el Alzheimer y la enfermedad del Parkinson que afecta a una de cada cien personas mayores de 65 años (De Rijk et al., 2000), ${ }^{6}$ en lo que respecta a las enfermedades infecciosas vale indicar que en México la más frecuente es la neurocisticercosis cerebral. ${ }^{7}$

Los tumores cerebrales llegar a adjudicarse entre el 10 y el 15\% de los tumores en el organismo y representan aproximadamente $25 \%$ de todas las muertes por cáncer (Álvarez-Lemus y López-Goerne, 2012). Se caracterizan por el crecimiento anormal de tejido dentro o adyacente al tejido cerebral normal, lo cual produce síntomas derivados de la presión aumentada en el cráneo o la compresión y destrucción de los tejidos cerebrales normales.

Se clasifican dependiendo, entre otros factores, del sitio exacto de ubicación, el tipo de tejido en el que se encuentran y el tipo de tendencia (alto o bajo grado). Los tumores primarios pueden originarse en las células del cerebro, meninges, nervios o glándulas (Ávarez-Lemus y López-Goerne, 2012).

Debido a su localización, todos los tumores cerebrales se consideran malignos, aunque, dependiendo de sus características microscópicas y su agresividad, hay algunos que pueden ser curables por medio de extirpación quirúrgica, como por ejemplo el grueso de meningiomas y adenomas de hipófisis. Otros pueden ser controlados en su crecimiento por largo tiempo como los oligodendrogliomas y los craniofaringiomas. En cambio, hay otros como el glioblastoma multiforme, resistente a todo tipo de terapia, por lo general asociado a pocos meses de vida. Desgraciadamente, en todos los casos el crecimiento de la masa de un tumor cerebral continua acabando el tejido y degradando las funciones principales del cerebro si se le deja sin tratamiento, esté último no pocas veces agresivo e impreciso.

Es notorio que la incidencia de los tumores primarios del sistema nervioso central, esté aumentando, especialmente en la población más joven, pues representa la segunda causa de muerte por cáncer en adultos menores de 35 años de edad. Entre los tumores cerebrales, casi la mitad de ellos se originan a partir de células gliales, es por ello que son clasificados como gliomas. Datos del National Caner Institute de EUA

\footnotetext{
6 El Alzheimer es una alteración neurodegenerativa primaria, que suele aparecer a partir de los 65 años, aunque también puede presentarse entre gente más joven. Cuando una persona padece la enfermedad, experimenta cambios nano y microscópicos en el tejido de ciertas partes de su cerebro y una pérdida, progresiva, pero constante, de una sustancia química, vital para el funcionamiento cerebral, llamada acetilcolina, que permite a las células nerviosas comunicarse entre ellas (Re et al., 2012: 53). En un principio, surgen pequeñas e imperceptibles pérdidas de memoria, pero con el paso del tiempo, esta deficiencia se hace cada vez más notoria e incapacitante para el afectado, que tendrá problemas para realizar tareas cotidianas, simples y algunas más complejas tales como hablar, comprender, leer, o escribir. Dependiendo de la etapa en que se encuentre el paciente, los síntomas son diferentes.

7 Los síntomas frecuentes son dolor de cabeza, convulsiones, trastornos de la vista, deterioro del estado de conciencia, e incluso la infestación masiva y la obstrucción del sistema ventricular o hidrocefalia. El tratamiento de la cisticercosis consiste en antiparasitarios, esteroides, anticonvulsivantes y en ocasiones procedimientos quirúrgicos.
} 
indican que $44.4 \%$ de los tumores cerebrales son de la familia de los gliomas, siendo el glioblastoma el más común con 51.9\%, seguido por el astrocitoma con el $21.6 \%$ de los casos (Allard et al., 2009; National Cancer Institute, 2005).

El régimen convencional de tratamiento del cáncer cerebral incluye la resección quirúrgica, radioterapia, quimioterapia sistémica y terapia fotodinámica (PDT, por sus siglas en inglés). Con todo, la media de supervivencia después de cirugía y radioterapia es de unos nueve meses, y sólo cerca del 10\% de los pacientes logran sobrevivir dos años (Burger y Green, 1987; Álvarez-Lemus y López-Goerne, 2012).

Los tumores pueden, pese a todo, arrojar células que invaden otras partes del cerebro formando tumores más pequeños, lo que torna difícil su detección mediante técnicas de imagenología convencionales (National Cancer Institute, 2005). Lo dicho toma relevancia cuando se anota que una de las principales dificultades que se presenta en el tratamiento de ciertos tumores cancerígenos es poder distinguir los márgenes del tumor y del tejido sano bajo condiciones quirúrgicas normales. Por tanto, aunque la cirugía suele ser la primera opción en tratamiento, ésta no es siempre una opción, más aun cuando estructuras elocuentes corren el riesgo de ser dañadas durante el procedimiento(Álvarez-Lemus y López-Goerne, 2012). En tales casos, el uso de radiación y drogas son la única ruta posible.

El tratamiento vía drogas tiene en cambio el gran reto de librar la barrera hematoencefálica (BHE), un sistema de vasos sanguíneos y células protectoras del cerebro que reduce al máximo la permeabilidad de sustancias (Loch-Neckel y Koepp, 2010). ${ }^{8}$

Debido a las alteraciones que sufre por traumatismos (edema cerebral e hipoxemia o disminución anormal de la presión parcial de oxígeno en sangre arterial cerebral), la BHE tiene claras consecuencias en el tratamiento y selección de medicamentos para los procesos patológicos del sistema nervioso central. Y es que se estima que incluso más del $95 \%$ de los fármacos suministrables no logran traspasarla y, cuando lo hacen, pueden llegar a dañar el material genético de las células sanas.

Ante tal panorama y dado que son muchos los factores que afectan y se presentan en la administración de fármacos, comúnmente vinculados con las reacciones metabólicas y bioquímicas cercanas a la nanoescala, la nanotecnología abre un potencial importante para eventualmente superar dichos problemas o retos.

Todo indica que en efecto hay ventajas significativas en el uso de nanoestructuras como vehículos de contraste (imagenología), suministro de fármacos y terapia, ello a diferencia de los mecanismos tradicionales. Destacan aspectos tales como: alta estabilidad; la posibilidad de transportar fármacos tanto hidrófilos como hidrófobos; alta capacidad de carga debido a su área de superficie mucho mayor; la posibilidad de controlar las tasas de liberación o de liberación con estímulos externos con una mayor biodisponibilidad; el hecho de que las dimensiones nanométricas hacen posible atravesar las barreras de las células (dígase cancerosas) y, en ciertos casos, parcialmen-

\footnotetext{
8 En el sistema nervioso central (SNC) los capilares sanguíneos son estructuralmente diferentes de los capilares de otros tejidos. Tales capilares, al estar cubiertos por células endoteliales especiales, sin poros y selladas con uniones estrechas, crean una barrera para las macromoléculas y compuestos como los antibióticos, entre otros fármacos. El endotelio capilar es la estructura que restringe el paso de las moléculas hidrofílicas al tejido nervioso. Los componentes que regulan el intercambio son los transportadores y enzimas que dejan cruzar elementos esenciales, como aminoácidos, glucosa, transferrina y sustancias neuroactivas como neuromoduladores y sus análogos, sustancias liposolubles como alcohol y esteroides. Las sustancias que entran al líquido cefalorraquídeo (LCR) ${ }^{8}$ se filtran a través de las células endoteliales y los astrositos.
} 
te la BHE; y el potencial del desarrollo de nanoplataformas multifuncionales para el diagnóstico y terapia dirigida simultáneamente (Aries et al., 2011).

Dicho de otro modo, los investigadores estudian cómo la nanotecnología puede ayudar a mantener los niveles de fármacos dentro del rango terapéutico; cómo pueden ser dirigidos a las zonas blanco (tumorales) y con liberación lenta; e idealmente explorando la posibilidad de reducir su toxicidad y efectos secundarios. En el desarrollo de sistemas de suministro de fármacos, por ejemplo, se está indagando el potencial de plataformas más eficientes mediante su diseño a escala nanométrica, al tiempo que se abre la posibilidad del desarrollo de termoterapia mediante el uso de nanopartículas metálicas o magnéticas que pueden ser estimuladas externamente con luz infrarroja o campos magnéticos.

\section{Breve metanálisis de publicaciones científicas en PubMed}

Según la base de datos de PubMed de EUA (pubmed.gov), desde el año 2000 y hasta junio de 2013 existían mas de tres mil artículos científicos publicados y registrados bajo las etiquetas de "nanotecnología” y “cáncer", concentrándose el grueso de resultados sobre todo en los últimos tres años y dibujándose ya claramente un espectro de investigación y resultados cada vez más amplios y complejos. Véanse en la tabla 1 mayores detalles de la progresión temporal tanto en los tipos de cáncer estudiados, como en técnicas y materiales nanoestructurados empleados (cada vez con una diversidad mayor de funcionalizaciones / conjugaciones).

Del total de publicaciones para ese periodo registradas en PubMed, alrededor del $44 \%$ se enfocó al área de diagnóstico; $50.5 \%$ a terapia; 3\% a metástasis; y sólo $2.5 \%$ a la prevención. En términos del tipo de cáncer, no más del 3\% de las publicaciones atendían en uno u otro grado alguna tipología de cáncer cerebral. Otros eran: $6 \%$ en cáncer de seno; $5 \%$ de pulmón; $4.5 \%$ de próstata; $4 \%$ de hígado; $2.5 \%$ de cáncer de piel; $2 \%$ leucemia; $2 \%$ de páncreas; $1.5 \%$ de cáncer de riñón; $1.5 \%$ de cáncer cervical. Estos últimos porcentajes, desde luego, deben leerse cuidadosamente pues mayoritariamente los artículos focalizados con algún tipo de cáncer suelen referirse a cuestiones de terapia o problemáticas de diagnóstico/caracterización específicas a cada caso. Por ello las proporciones han de ser leídas, comparativamente hablando, sólo entre los rubros de artículos focalizados a algún tipo de cáncer y no con respecto al total de artículos publicados y registrados en PubMed en tanto que muchas publicaciones no figuran en algún rubro particular al tener implicaciones para múltiples tipologías de cáncer.

En relación con los artículos focalizados, en una u otra medida, en cáncer cerebral, ésos sumaban sólo 86 para el mismo periodo de tiempo. El grueso de las publicaciones datan de 2011 a la fecha. ${ }^{9}$ En términos generales, sugieren para el área de diagnóstico (incluyendo imagenología) el uso de nano-bio marcadores (aptámeros); sondas fluorescentes de nanopartículas como agentes contrastantes; nanopartículas superparamagnéticas (para imagenología de resonancia magnética) y magnéticas; y puntos cuánticos. Para el caso del área de tratamiento (terapia / entrega de droga) se indaga el potencial de nanopartículas (superparamagnéticas, magnéticas,

\footnotetext{
9 El número de artículos por año es: dos en 2003; tres en 2004; tres en 2005; cuatro en 2006; siete en 2007; ocho en 2008; nueve en 2009; trece en 2010; once en 2011; veintiuno en 2012; cinco hasta junio de 2013.
} 
biodegradables base PLGA, de base lípido, de sílice, poliestireno carboxilado, platino); fulerenos; vesículas extracelulares; nanoalambres; grafeno; nanotubos de carbono multipared (como nanovehículos de entrega de droga o genes); y aptámeros conjugados con nanopartículas. Además, se menciona el uso de láseres para terapia y la apuesta por la denominada neuroteranostics, es decir, la mencionada integración del diagnóstico y la terapia de cáncer cerebral en un solo sistema nanoestructurado (Kievit y Zhang, 2011).

TABLA 1. Publicaciones sobre cáncer y nanotecnología registradas en PubMed, 2000-2013

\begin{tabular}{|c|c|c|c|}
\hline Año & $\begin{array}{l}\text { No de } \\
\text { artículos }\end{array}$ & $\begin{array}{c}\text { Tipo de cáncer } \\
\text { (en caso de especificarse) }\end{array}$ & $\begin{array}{l}\text { Finalidad de nanotecnologías o nanomateriales empleados } \\
\text { (especificaciones principales tal y como se enuncian) }\end{array}$ \\
\hline 2000 & 2 & Cáncer de seno & $\begin{array}{l}\text { Detección } \\
\text { Diagnóstico }\end{array}$ \\
\hline 2001 & 9 & $\begin{array}{l}\text { Cáncer cervical, de próstata y } \\
\text { de seno } \\
\text { Melanomas } \\
\text { Tumores sólidos } \\
\text { Micrometástasis }\end{array}$ & $\begin{array}{l}\text { Imagen / Caracterización de tumores } \\
\text { Tratamiento: nanoesféras, nanopartículas. }\end{array}$ \\
\hline 2002 & 46 & $\begin{array}{l}\text { Cáncer de hígado, páncreas, } \\
\text { colón. }\end{array}$ & $\begin{array}{l}\text { Imagen avanzada / Medición / Caracterización: nanosensores, materiales porosos, nanoes- } \\
\text { feras puntos cuánticos. } \\
\text { Detección temprana. } \\
\text { Terapia / Entrega de droga: nanocristales, nanoesferas, nanopartículas, nanopartículas super- } \\
\text { paramagnéticas, nanocápsulas, sistemas nanoestructurados tipo virus. } \\
\text { Terapia de captura neutrónica }\end{array}$ \\
\hline 2003 & 68 & $\begin{array}{l}\text { Cáncer cervical, oral, cerebral, } \\
\text { de próstata, epidérmico. } \\
\text { Tumores sólidos }\end{array}$ & $\begin{array}{l}\text { Imagen / Biomarcadores / Monitoreo de metástasis: cromatografía líquida de nanoflujo aco- } \\
\text { plada a ionización por electrospray; inmuno conjugados de puntos cuánticos; nanopartículas } \\
\text { contrastantes. } \\
\text { Terapia / Entrega de droga: nanopartículas biodegradables, cerámicas, magnéticas, autoen- } \\
\text { sambladas; nanoshells; drogas coloidales. }\end{array}$ \\
\hline 2004 & 84 & $\begin{array}{l}\text { Cáncer de riñón, hígado, de } \\
\text { pulmón, de seno, de vejiga, } \\
\text { colon, próstata, de la glándula } \\
\text { pituitaria o hipófisis. } \\
\text { Tumores sólidos. } \\
\text { Leucemia. } \\
\text { Glioblastoma }\end{array}$ & $\begin{array}{l}\text { Prevención: nanovacunas contra tumores. } \\
\text { Imagen / Detección: nanobiosensores / biochips; proteínas fluorescentes utilizando nano- } \\
\text { biohíbridos; puntos cuánticos; conjugados de nanocuerpos, es decir, de los fragmentos más } \\
\text { pequeños de anticuerpos de dominio único; nanopartículas recubiertas para se dirigidas a } \\
\text { objetivos específicos. } \\
\text { Nanoproteómica de líneas celulares cancerosas. } \\
\text { Tra Terapia / Entrega de droga: quimioterapia con nanopartículas biodegradables, superpara/ } \\
\text { magnéticas; dendrímeros; nanocápsulas; nanoesféras; nanoshells. }\end{array}$ \\
\hline 2005 & 116 & $\begin{array}{l}\text { Leucemia } \\
\text { Cáncer de seno, pulmonar, de } \\
\text { piel (fibroblastos), gástrico, de } \\
\text { pulmón, de colon, epitelial. }\end{array}$ & $\begin{array}{l}\text { Diagnóstico / Imagen: nanodiagnóstico fototérmico con nanoclusters autoensamblados; } \\
\text { nanobiosensores, nanosensores ópticos, puntos cuánticos; nanoláser ultrarrápido para detec- } \\
\text { ción biofotónica, nanopartículas; redes de sensores de nanocables. } \\
\text { Terapia / Entrega de droga: nanopartículas dirigidas, materiales inorgánicos, nanocápsulas } \\
\text { (de alumina nanoporosa, poliméricas), micelas, nanotubos de carbono, partículas magnéticas } \\
\text { (termoterapia), partículas paramagnéticas, terapia de genes dirigidos, nanoemulsiones, lipo- } \\
\text { somas, nanocuerpos, dendrímeros, nanocristales, nanoesferas, nanosondas. }\end{array}$ \\
\hline 2006 & 163 & $\begin{array}{l}\text { Cáncer de ovario, gástrico, } \\
\text { renal, de piel, pulmonar, naso- } \\
\text { faringeal, de seno, cerebral, de } \\
\text { colón, de próstata - genitouri- } \\
\text { nal, oral - de lengua, uterino. } \\
\text { Sarcoma de Ewing. }\end{array}$ & $\begin{array}{l}\text { Diagnóstico / Imagen: bionanomarcadores, nanopartículas, puntos cuánticos, nanotubos de } \\
\text { carbono (monopared), nanovehículos, nanosondas, nanoblob contrastante (nanoemulsión } \\
\text { de moléculas anfifílicas con su parte hidrofílica apuntando hacia fuera). } \\
\text { Terapia / Entrega de droga: nanotubos de carbono (multi- y monopared), nanopartículas } \\
\text { (poliméricas biodegradables, ácido sensibles, metálicas, magnéticas, bioconjugadas), ge- } \\
\text { noesferas, nanoestructuras tipo tetrapoides, nanomateriales core-shell, puntos cuánticos } \\
\text { / nanocristales, micelas y péptidos autoensamblables, liposomas, nanoplataformas (nano- } \\
\text { partículas multifuncionales), dendrímeros, fulerenos }\left(C_{60}\right) \text {, nanogeles, nanocompositos, na- } \\
\text { noblobs dirigidos para entrega de agente quimioterapéutico, campos eléctricos pulsados a } \\
\text { nanosegundos (para destrucción de melanomas), exosomas como nanovehículos (vesículas } \\
\text { muy pequeñas). } \\
\text { Nanoneurocirugia (incluyendo el potencial uso de sistemas de láser ultra-rápidos, nanoagujas } \\
\text { y nanopinzas) + bionanoinformática para oncología personalizada. }\end{array}$ \\
\hline
\end{tabular}




\begin{tabular}{|c|c|c|c|}
\hline Año & $\begin{array}{l}\text { No de } \\
\text { artículos }\end{array}$ & $\begin{array}{l}\text { Tipo de cáncer } \\
\text { (en caso de especificarse) }\end{array}$ & $\begin{array}{l}\text { Finalidad de nanotecnologías o nanomateriales empleados } \\
\text { (especificaciones principales tal y como se enuncian) }\end{array}$ \\
\hline 2007 & 200 & $\begin{array}{l}\text { Cáncer pulmonar, de piel - sar- } \\
\text { coma de Kaposi, sarcomas di- } \\
\text { versos, cáncer de próstata, de } \\
\text { seno, cerebral, gastrointestinal } \\
\text {, de vejiga, de colon y recto. } \\
\text { Leucemia, colangiocarcinoma. }\end{array}$ & $\begin{array}{l}\text { Diagnóstico: puntos cuánticos, nanopartículas (fluorescentes, magnéticas, superparamag- } \\
\text { néticas, metálicas), nanoestructuras de carbono, electrodos base nanotubos de carbono, } \\
\text { polímeros, nanohíbridos magneto-poliméricos, nanosensores. } \\
\text { Terapia / Entrega de droga: nanotubos de carbono monopared y multipared (terapia tér- } \\
\text { mica, nanovehículos para entrega de droga); dendrímeros y dendrímeros conjugados (con } \\
\text { nanopartículas); liposomas funcionalizados y enjaulados en polímeros; nano shells (oro, sí- } \\
\text { lica); nanopartículas magnéticas, poliméricas (péptidos), metálicas, mesoporosa, fotosensiti- } \\
\text { vas (para terapia fotodinámica) y funcionalizadas; micelas funcionalizadas (copoliméricas); } \\
\text { nanovesículas; drogas herbales chinas a escala nanométrica (nanoprecipitado); nanocajas y } \\
\text { nanorodillos de oro conjugados; nanogeles, hidrogeles de nanodiamantes; esferas y prismas } \\
\text { nanoestructurados; estructuras multicapa de láminas de nanopartículas, virus funcionaliza- } \\
\text { dos a escala nanométrica. }\end{array}$ \\
\hline 2008 & 251 & $\begin{array}{l}\text { Cáncer de páncreas, de seno, } \\
\text { intraocular, de colon y ano- } \\
\text { rectal, de próstata, cerebral } \\
\text { (neuroblastoma), de hígado, } \\
\text { de vejiga, de hueso, de piel. } \\
\text { Leucemia, linfomas. }\end{array}$ & $\begin{array}{l}\text { Diagnóstico: nanoparticulas (magnéticas, superparamagnéticas, metálicas, de compositos, } \\
\text { conjugadas y funcionalizadas, PLA-TPGS, fotosensibles), puntos cuánticos (sondas fluores- } \\
\text { centes, contrastantes), nanotubos, dendrímeros, conjugados de aptámeros, nanorrodillos. } \\
\text { Terapia / Entrega de droga: nanopartículas (de lípidos, core-shell, mesoporosas, conjuga- } \\
\text { das y funcionalizadas); nanopolímeros, nanotubos monopared funcionalizados, nanogeles, } \\
\text { nanopipetas de carbono, nanorrodillos, nano-micelas, nanocajas de oro, nanodiamantes, } \\
\text { dendrímeros conjugados,"nanorobots" (bacterias flageladas como bio-actuadores dirigidos } \\
\text { a tumores), nanoconjugados, vehículos coloidales para la entrega de droga, nano-vesículas } \\
\text { (polimersomas), nanofibras, nanodiscos. } \\
\text { Nanoteranostics (uso de nanopartículas magnéticas multifuncionales) }\end{array}$ \\
\hline 2009 & 377 & $\begin{array}{l}\text { Carcinoma gástrico, de colon- } \\
\text { recto, de próstata, de ovario, } \\
\text { de pulmón, de seno, de cere- } \\
\text { bro - neuroblastoma, de riñón, } \\
\text { de hígado, de páncreas. } \\
\text { Leucemia. }\end{array}$ & $\begin{array}{l}\text { Diagnóstico: nanopartículas (metálicas, magnéticas, superparamagnéticas), nanobiosensor } \\
\text { (base nanofibras / polímeros); nanobarras; dendrímeros (+conjugados); nanodiamantes / } \\
\text { nanocristales (fluorescentes); bioconjugados de puntos cuánticos; puntos cuánticos (tipo } \\
\text { core-shell, semicondutores fluorescentes); nanomicelas poliméricas fosforescentes. } \\
\text { Terapia / Entrega de droga: nanopartículas (metálicas, magnéticas, conjugadas con proteí- } \\
\text { nas, coloidales, tipo virus, mesoporosas, PLGA, core-shell); nanocápsulas poliméricas / de } \\
\text { lípidos; conjugados de copolímeros / péptidos; nanovehículos fotosensibles; nanotubos de } \\
\text { carbono (mono y multipared); nanobarras (terapia térmica); nanoemulsiones; nanoalambres; } \\
\text { dendrímeros; nano-micelas; nanocristales. } \\
\text { Terasnostics (nanopartículas magnéticas). } \\
\text { Vacunas: vehículos nanoestructurados de entrega de vacunas. }\end{array}$ \\
\hline 2010 & 507 & $\begin{array}{l}\text { Cáncer de ovario, de próstata, } \\
\text { sarcomas, páncreas, de colon, } \\
\text { cervical, de seno, de pulmón, } \\
\text { cuello cabeza, cerebral -glio- } \\
\text { blastoma -intercraneales, gástri- } \\
\text { co, de vejiga, genitario-urinario. } \\
\text { Leucemia. }\end{array}$ & $\begin{array}{l}\text { Diagnóstico: puntos cuánticos (funcionalizados), nanoesferas, nanocompositos magnéticos } \\
\text { termosensitivos; nanocomposites bifuncionales; nanosondas fluorescentes; nanosondas de } \\
\text { aleación oro-plata; nanobarras, nanopartículas metálicas, magnéticas y superparamagnéticas. } \\
\text { Terapia / Entrega de droga: liposomas conjugados; péptidos; micelas (poliméricas); nano- } \\
\text { partículas (linfotrópicas, poliméricas, poliméricas-liposomas, de copolimeros biodegradables, } \\
\text { metálicas, PLGA, de lípidos, de polifenoles, mesoporosas, superparamagnéticas, magnéticas, } \\
\text { coloidales, virales, core-shel/); nanobarras; nanoemulsiones; dendrímeros, puntos cuánticos, } \\
\text { nanotubos de carbono (mono y multipared), nanoesferas, nanocompositos magnéticos } \\
\text { termosensitivos, nanogeles, aptámeros conjugados con nanopartículas magnéticas (como } \\
\text { 'nanocirujanos'), nanocristales en forma de barras; nanodiamantes; nanocajas; nanocontene- } \\
\text { dores base carbono; superficies de titanio con adhesiones de clústers de selenio; metalofule- } \\
\text { renos; protacs (nanomoleculas heterobifuncionales). } \\
\text { Terasnostics (clusters de puntos cuánticos conjugados, nanoburbujas plasmónicas, nanotu- } \\
\text { bos de carbono; exploración del potencial futuro de nanorobots). } \\
\text { Cirugía: láser ultrarrápido para nanocirugía; } \\
\text { Vacunas: vehículos nanoestructurados de entrega de vacunas (exosomas). }\end{array}$ \\
\hline 2011 & 603 & $\begin{array}{l}\text { Cáncer de pulmón, linfático, de } \\
\text { próstata, de hueso, de seno, de } \\
\text { colon, de cuello-cabeza - glio- } \\
\text { blastomas - cerebro, de ovario, } \\
\text { cervical, de vejiga, de páncreas, } \\
\text { naso-faringeal. } \\
\text { Leucemia. }\end{array}$ & $\begin{array}{l}\text { Diagnóstico: nanobarras (fluorescentes); nanopartículas (superparamagnéticas, magnéticas, } \\
\text { magnéticas multi-núcleo, mesoporosas, core-shell); nanotubos de carbono monopared y } \\
\text { multipared; fulerenos, nanoesferas fluorescentes; puntos cuánticos, nanoclusters metálicos, } \\
\text { magnetoliposomas. } \\
\text { Terapia / Entrega de droga: nanoliposomas, magnetoliposomas; nanoparticulas core-shell, } \\
\text { superparamagnéticas, magnéticas, metálicas, mesoporosas, PLGA; conjugados de nanopartí- } \\
\text { culas; nanobarras-dendrímeros; nanosuspenciones; fulerenos inmunoconjugados; nanotubos } \\
\text { (titanato), nanotubos de carbono mono y multipared, nanotubos conjugados / funcionaliza- } \\
\text { dos; puntos cuánticos; nanosomas; conjugados de nanocajas; grafenos; aptámeros (conjuga- } \\
\text { dos); dendrímeros; metalo-fulerenos; biocerámicas nanoestructuradas; micelas poliméricas; } \\
\text { nanogeles, nanofibras (anfifilicas), nanoalambres, nanodiscos, nanodiamantes, nanocamas } \\
\text { de carbono de puntos cuántico y nanopartículas magnéticas. } \\
\text { Terasnostics (nanocajas / nano-bio-compositos multifuncionales, nanotubos y puntos cuánticos) } \\
\text { Cirugía: láser ultrarrápido para nanocirugía. } \\
\text { Vacunas: vehículos nanoestructurados de entrega de vacunas. }\end{array}$ \\
\hline
\end{tabular}




\begin{tabular}{|c|c|c|c|}
\hline Año & $\begin{array}{l}\text { No de } \\
\text { artículos }\end{array}$ & $\begin{array}{c}\text { Tipo de cáncer } \\
\text { (en caso de especificarse) }\end{array}$ & $\begin{array}{l}\text { Finalidad de nanotecnologías o nanomateriales empleados } \\
\text { (especificaciones principales tal y como se enuncian) }\end{array}$ \\
\hline 2012 & 599 & $\begin{array}{l}\text { Cáncer de seno, de hueso, de } \\
\text { pulmón, de ovario, de próstata, } \\
\text { grastrointestinal, oral, de colon } \\
\text { y recto, de cabeza y cuello, } \\
\text { glioblastoma, de páncreas, de } \\
\text { piel. } \\
\text { Sarcoma de Ewing. } \\
\text { Leucemia. }\end{array}$ & $\begin{array}{l}\text { Diagnóstico: nanorrodillos; puntos cuánticos; sondas (core shell, base aptámeros y puntos } \\
\text { cuánticos o nanodiamantes fluorescentes; micelas; nanoparticulas metálicas, core-shell, plas- } \\
\text { mónicas y virales; grafeno (fluorescente); nanoemulsiones; nanoprismas (de oro); nanotu- } \\
\text { bos monopared luminiscentes; nanoparticulas bifuncionales (para resolución magnética y } \\
\text { fluorescencia). } \\
\text { Terapia / Entrega de droga: nanopartículas (metálicas, recubiertas de lípidos, tipo-lipopro- } \\
\text { teínas, poliméricas, mesoporosas, magnéticas, core-shell, LSMO, PLGA, PLA-TPGS, RNA fun- } \\
\text { cionalisadas con siRNAs, base exopolisacarida); nanomateriales/nanopartículas a partir de } \\
\text { proteínas (virales); nanotubos de carbono mono y multipared + conjugados - funcionalizados } \\
\text { (terapia térmica y entrega de droga); nanorrodillos (terapia térmica); nanodispositivos base } \\
\text { biopolímeros; ligandos; nanosistemas de carbono activados por luz laser; micelas; bioconju- } \\
\text { gados de nanopartículas de sílice y aptámeros; conjugado de dendrímeros y geles híbridos } \\
\text { de colágeno; nanocristales; nanofibras conjugadas; plataformas de entrega de droga base } \\
\text { grafeno-titania; nanoestructuras acopladas a anticuerpos recombinantes; nanocajas; nanoa- } \\
\text { lambres; nanobarras cuánticas. } \\
\text { Nanovehículos para terapia génica por inhalación; exploración de entrega de quimioterapia } \\
\text { vía oral con nanoestructuras funcionalizadas. } \\
\text { Terasnostics (uso de nanoestructuras lípido-poliméricas, tratamiento multimodal, nanopartí- } \\
\text { culas core-plasmonic shell tipo estrella) } \\
\text { Cirugía: sonda asistida con nanoelectrospray de espectrometría de masas de ionización para } \\
\text { el diagnóstico de tejidos biológicos (sanos o cancerosos). Una versión comercial fue lanzada } \\
\text { en } 2013 \text { bajo el nombre de iKnife con un retraso de análisis de } 3 \text { segundos. } \\
\text { Vacunación: exploración de opciones para vacunas orales nanoestructuradas. }\end{array}$ \\
\hline $\begin{array}{c}2013 \\
\text { (Junio) }\end{array}$ & 218 & $\begin{array}{l}\text { Cáncer de seno, de hueso, de } \\
\text { pulmón, de próstata, de riñón, } \\
\text { de ovario - útero, oral, gastro- } \\
\text { intestinal, de colon, de hígado, } \\
\text { cerebral - neoplasmas inter- } \\
\text { craneanos, cáncer de cuello. }\end{array}$ & $\begin{array}{l}\text { Prevención: polifenoles como terapia químico-preventiva. } \\
\text { Diagnóstico / Imagen: nanotubos monopared, nanopartículas (magnéticas, metálicas), mice- } \\
\text { las, fulerenos, puntos cuánticos, nanosondas, nanoplataformas (de silicón). } \\
\text { Terapia / Entrega de droga: nanoestructuras funcionalizadas con ADN, nanocápsulas, na- } \\
\text { nopartículas funcionalizadas (metálicas, magnéticas, paramagnéticas y superparamagnéti- } \\
\text { cas), nanotubos multi- y monopared (terapia térmica, como nanovehículo funcionalizado), } \\
\text { nanogeles / nanocompositos hidrogel, micelas (biodegradables), nanomateriales core-shell, } \\
\text { grafeno, dendrimeros, nanosondas, nanotrenes, nanofibras, nanoalambres, puntos cuánti- } \\
\text { cos funcionalizados, nanovarillas (metálicas), nanocubos, nanoesferas, nanoprismas (de oro). } \\
\text { Nutraceuticals para tratamiento de cáncer oral } \\
\text { Nanoteranostics }\end{array}$ \\
\hline Total & $3,243^{*}$ & & \\
\hline
\end{tabular}

* Se estima que el número total de artículos relacionados a la nanomedicina es $\sim 10 \%$ menor, pero no más. Se verificaron algunos artículos que aunque mencionaban la palabra "cáncer" no estaban enfocados a tal temática, pero sobre todo, las búsquedas por año derivan en repeticiones en tanto que aparecen artículos de años anteriores al ser identificados por la fecha de aceptación y no de publicación. El número total de artículos para el periodo de estudio es: 2,979.

Nota: la división entre materiales nanoestructurados para diagnóstico, tratamiento y entrega de droga es cada vez más borrosa, lo que se evidencia con el propio uso de teranostics. En ese sentido, la clasificación es básicamente para propósitos analíticos, siguiendo la propuesta de enfoque que cada artículo otorga.

Fuente: Elaboración propia a partir de análisis base de publicaciones registradas en PubMed.

Algunas investigaciones destacan distintos avances concretos. Por ejemplo, como describe Hickey (2009), un grupo de investigadores de la Universidad de Washington, dirigido por Miqin Zhang, ha conseguido "pintar" tumores cerebrales inyectando nanopartículas fluorescentes en el torrente sanguíneo. Estas nanopartículas son capaces de atravesar la BHE. En experimentos de laboratorio, los científicos han mostrado que las nanopartículas en cuestión permanecieron en tumores de ratón durante cinco días y no hubo evidencia alguna de que causarán daños en la BHE; al menos durante dicho periodo de tiempo.

Los resultados muestran que las nanopartículas mejoran el contraste en los escaneos mediante resonancia magnética (MRI, por sus siglas en inglés) y en las imágenes 
ópticas, una clara ventaja no sólo para detección temprana de cáncer, sino también para que los cirujanos, al momento de intervenir quirúrgicamente, puedan "ver" con mayor precisión la frontera entre el tejido canceroso y sano(las técnicas actuales de obtención de imágenes tienen una resolución máxima de 1 milímetro) (Hickey, 2009). Lo relevante de la investigación señalada es que, hasta entonces, ninguna nanopartícula usada para obtener imágenes había podido cruzar la barrera hematoencefálica y enlazarse específicamente a las células tumorales (Ibid.). Los retos, sin embargo, aún son mayores y las lagunas de conocimiento notorias. Por ejemplo, el mecanismo exacto del transporte de la nanoparticula dentro del cerebro, según precisan los propios investigadores, aún no se entienden completamente. Se cree que depende del tamaño de la partícula, la composición del material y la estructura. En algunos casos, parece que un recubrimiento especializado de polímero es lo que permite que las nanopartículas puedan imitar moléculas que normalmente serían transportadas dentro del cerebro (Ibid.).

Otra investigación, como informa el National Cancer Insitute (2005) muestra que nanopartículas «decoradas» con péptidos opioides son capaces de unirse a receptores específicos en las paredes de los capilares, ayudando a transportar las nanopartículas en el cerebro. Una vez dentro del cerebro, una nanopartícula puede suministrar una amplia variedad de cargas útiles para detectar células cancerosas (Ibid.).

Los resultados de otro estudio develan que las nanopartículas de dióxido de titanio, un material fotocatalítico (sensible a la luz), pueden destruir algunas células de cáncer cuando la sustancia se expone a la luz ultravioleta (Rozhkova, 2011). Sin embargo, la dificultad para dirigir las nanopartículas de $\mathrm{TiO}_{2}$ a células cancerosas ha precisado el desarrollo de tales nanopartículas unidas químicamente a un anticuerpo que reconoce y se une a las células, en este caso de glioblastoma multiforme (GMB) (Ibid.). Cabe precisar que la exposición de dicho material en cultivos de laboratorio resultó en la destrucción de alrededor del 80\% de las células cancerosas después de cinco minutos de exposición a luz blanca focalizada. Los resultados sugieren, según los investigadores, que estas nanopartículas podrían convertirse en una parte prometedora de la terapia de cáncer cerebral cuando se usan durante la cirugía (Ibid.).

En otras investigaciones se procura disminuir, en los procedimientos quirúrgicos de GMB, la ya mencionada dificultad de distinguir visualmente las células sanas de las cancerosas, una cuestión que suele resultar en un retiro incompleto del tejido dañado y que no en pocas ocasiones deviene en metástasis (entre 10 y 15\% de los pacientes con cáncer desarrolla eventualmente tumores matásticos cerebrales; National Cancer Institute, 2005). Las investigaciones realizadas en México por López-Goerne y colaboradores (2007, 2008, 2010 y 2011) se perfilan en tal dirección. Según sostienen, la inyección de nanopartículas $\mathrm{Pt}(\mathrm{NH} 3) 4 \mathrm{Cl} 2 / \mathrm{SiO} 2$ directamente en el tumor es viable en tanto que las células cancerosas son susceptibles a recibirlas (López-Goerne et al., 2011). La investigación en cuestión se ha realizado en ratas Wistar mostrando, según se indica, resultados positivos, pues se cree que la muerte de células cancerosas deviene de los radicales libres que inducen daño al ADN: el tumor en las ratas enfermas disminuye a los 30 días de la aplicación de entre 50\% a 80\% (López-Goerne et al., 2011; Peralta, 2012). ${ }^{10}$ Según la Dra. López, aquellos ratones que han dejado vivir, el tumor incluso ha llegado prácticamente a desaparecer (Peralta, 2012). Las prue-

${ }^{10}$ El dato preciso, en López et al., 2011, es de 73 por ciento. 
bas clínicas son el siguiente paso, lo que aparentemente se hace con pacientes en fase terminal en el Instituto Nacional de Neurología y Neurocirugía <www.innn.salud.gob. $\mathrm{mx} /$ interior/investigacion/departamentos/nanotecnologia.html>.

El mapeo general de las áreas y nanomateriales explorados en las publicaciones registradas en PubMed, así como los casos meramente ilustrativos antes expuestos, dejan ver nítidamente el avance y potencial que se vislumbra en el uso de la nanotecnología para el diagnóstico y tratamiento del cáncer cerebral.

Como todo avance tecnológico, pero particularmente en el que a la salud refiere, las implicaciones son amplias y trascienden cuestiones técnicocientíficas sobre toxicidad y efectos secundarios (véase más adelante) al internalizar cuestiones éticas y sociales: desde los contextos y riesgos "válidos" en las pruebas clínicas, la comunicación médico-paciente y el acceso a información y material biológico de los segundos; hasta cuestiones de (in)justicia social asociadas al real acceso a tales o cuales avances tecnológicos por parte de la sociedad.

\section{UN ENFOQUE ÉTICO Y RESPONSABLE PARA LAS NANOTECNOLOGÍAS Y LA NANOMEDICINA: CONSIDERACIONES GENERALES}

Como ha sucedido con la biotecnología y tecnologías emergentes, para el caso de las nanotecnologías es necesario un análisis ético a cerca de las implicaciones sociales, éticas, legales y ambientales, incluyendo los eventuales riesgos y alcances que tales tecnociencias podrían traer consigo al momento de ser desarrolladas y socializadas. Se trata de una ética que se fundamenta en una democracia informativa y deliberativa, esto es, aquella construida sobre la base de un amplio y activo diálogo. Para el caso puntual de la nanomedicina, dicha ética debería trascender pero desde luego incluir, las controversias médicas. Una ética panorámica ${ }^{11}$ (más allá de una focalizada — dígase en las mencionadas controversias) demanda también discutir tanto la pertinencia y justificación de dicho frente tecnocientífico de cara a otras alternativas y demandas sociales, así como la naturaleza misma de su propio avance, sus complejidades y grados de incertidumbre, las estructuras de poder presentes, entre otros (al respecto léase: Strand y Nydal, 2008; De Cozar, 2010; Delgado en Arnaldi et al., 2011; Lupton, 2011).

Las innovaciones nanotecnológicas suscitan, además, la emergencia de nuevas entidades, de nuevas prácticas sociales e incluso de nuevas interacciones alrededor de la solución tecnológica generada; tantas como la amplitud de aplicaciones nanotecnológicas en desarrollo. Por tanto, resulta central llevar a cabo una evaluación ética - panorámica y focalizada- de las nanotecnologías como parte fundamental de un ejercicio continuo, pues mientras más se desconozca, por un lado, sobre las complejidades e incertidumbres presentes en el acelerado avance de las nanotecnologías, y por el otro, sus implicaciones (lo que está en juego), mayores serán las dificultades para su desarrollo responsable y regulación democrática. ${ }^{12}$

Anteriormente se describieron algunas de las investigaciones y problemas en el diagnóstico y tratamiento del cáncer cerebral, señalando sintética y brevemente al-

\footnotetext{
${ }^{11}$ Seguimos la propuesta de Strand y Nydal, 2008.

${ }^{12}$ Entiéndase por democracia un proceso que no se limita a la democracia representativa sino que en cambio tiende más hacia una diversidad de formas de democracia participativa.
} 
gunas de las investigaciones en nanotecnología y nanomedicina prometedoras. Dado que el grueso de las soluciones implica la exposición directa del cuerpo humano a diversos nanomateriales diseñados por el ser humano, es más que pertinente cuestionar qué tanto se conocen sus características, cuáles son sus propiedades eco-toxicológicas (Tsuda et al., 2009; Yoshioba et al., 2010; Sharma, 2010), cómo se realizan las evaluaciones de riesgo y cuáles son sus limitaciones (Wickson, 2011). Y es que como sostiene De Cozar, (2010: 36), la mayoría de las investigaciones están en plena experimentación, presentándose así grados de incertidumbre por falta de conocimiento en tanto que las consecuencias e implicaciones que le subyacen a dichos experimentos con nanomateriales no son aún bien conocidas y están en constante investigación (De Cozar, 2010: 36).

Así entonces, en el corto plazo, posibles riesgos toxicológicos asociados al uso de nanomateriales (considerando también los espacios de fabricación, por ejemplo, de fármacos; léase Murashov, 2009) representan la preocupación más importante dado que las consecuencias indeseables son posibles, resultantes, por ejemplo, de la capacidad de los nanomateriales de penetrar e interactuar con la célula y sus componentes; precisamente una característica que, como se dijo, es atractiva en el desarrollo de drogas dirigidas "nanoempaquetadas" (Delgado en Arnaldi et al., 2011: 87). La apuesta, tecnológicamente hablando, está entonces en buscar materiales inertes o pasivados (mediante su "decoración"), pero debido a la complejidad de los nanomateriales y de los ámbitos de interacción — dígase, el cuerpo humano- ello no se puede asegurar en todos los casos sin algún grado de incerteza; de ahí la necesidad de ser precavidos.

Algunas consideraciones toxicológicas de los sistemas de entrega de droga a la nanoescala de hecho son ya discutidas en la literatura (Sharma et al., 2012). Y es que la ecotoxicidad de los materiales nanoestructurados está relacionada simultáneamente con varios aspectos: 1) el tipo de organismo receptor; 2) la magnitud y duración de la exposición; 3) la persistencia del material, 4) la toxicidad inherente, y, 5) la susceptibilidad o el estado de salud del receptor.

El dilema no está sólo en el propio proceso de respuesta a las preguntas y retos arriba expuestos, sino en cómo al tiempo que avanzan las nanotecnologías, se gestiona y regula oportuna y adecuadamente la socialización de los productos generados a partir de tales o cuales nanomateriales. Lo pertinente sin duda es la investigación exhaustiva respecto a la ecotoxicidad de los nanomateriales, comenzando por los de mayor potencial en términos de uso (cantidad), pero también por aquellos cuyo grado de exposición directa al cuerpo humano se estime particularmente delicada o mucho mayor. ${ }^{13}$ Un esfuerzo integral debiera incluir, además, un constante escrutinio de los propios modelos de evaluación del riesgo e, idealmente, apostar por un sistema de evaluación de pares abierto (Funtowicz y Ravetz, 1990; Funtowicz y Strand, 2007; Wickson, 2011).

No deja de ser llamativo que pese su importancia, ese tipo de investigaciones, sobre todo las últimas, sigan siendo comparativamente muy limitadas de cara a las

\footnotetext{
${ }^{13}$ Debe reconocerse que, aunque aún no suficiente, cada vez más se están indagando cuestiones sobre ecotoxicidad de los nanomateriales y sus implicaciones. Algunas referencias relevantes al respecto son: Oberdorter et al., 2002 y 2004; Ynag y Watts, 2005; Lovern y Klaper, 2006; Shatkin, 2008; Poland, 2008; Song, Li y Du, 2009; Li et al., 2009; Mikkelsen, Hansen y Christensen, 2011; Nazarenko et al., 2012;; Jastrzebska, Kurtycz y Olszyna, 2012; CDRSEHSAEN, 2012; Bachand et al., 2012; Arvidsson, 2012.
} 
que buscan una aplicación concreta (Sin autor, 2006-A y 2006-B; Rejeski, 2005; EPA, 2005). ${ }^{14}$ Tampoco el hecho de que en general no existen los mecanismos y condiciones para estimular de modo prioritario tales investigaciones e incluso, los requisitos técnocientíficos adecuados para hacer ampliamente comparables las evaluaciones de riesgo de los nanomateriales. Y, aunque ciertamente estos últimos se están afinando (por ejemplo, en el marco de la ISO/TC229; véase ISO, 2008 y 2010), en diversos países donde se hace investigación, siguen sin desarrollarse medidas propias. Por ejemplo, el trabajo de estandarización y de generación de materiales de referencia no se ha realizado o está en proceso pero sin ser aún operativo y con consecuencias regulatorias, tanto en lo que respecta en sí a los patrones de medida "nano", como a los protocolos de investigación, evaluación y comparabilidad de resultados. Esto último aún es el caso de México.

Lo antes delineado se considera central para poder dar pie a una regulación informada y responsable que busque maximizar y socializar los beneficios y minimizar (o incluso evitar) los eventuales riesgos e implicaciones no deseadas (Delgado, 2008). Con tal fin, la figura 3 presenta esquemáticamente un aproximación genérica a los principales elementos que normativamente conformarían un modelo integral de gestión y distribución del riesgo, en este caso de la nanobiomedicina; todo desde la perspectiva antes descrita.

El modelo incluye, como puede notarse, el cálculo y valoración de las implicaciones, la incertidumbre y el riesgo, así como un proceso de legitimación y justificación de la medidas para estimular y regular la nanobiomedicina incluyendo el consentimiento previo e informado (léase: Jotterand y Alexander, 2011) y, de ser necesario y pertinente, la aplicación del principio precautorio con la finalidad de evitar "lecciones tardías de advertencias tempranas" (EEA, 2001 y 2013).

El desarrollo responsable y precautorio de las nanotecnologías en los diversos campos de aplicación no significa desconocer su potencial tecnocientífico y, con ello, las posibilidades reales de contribuir con la resolución de problemas diversos (además de la posibilidad de desarrollar capacidades tecnológicas propias vinculadas con las necesidades sociales de tal o cual país).

En todo proceso de innovación hay potenciales beneficios, costos y riesgos (aunque ciertamente de magnitud y naturaleza diferenciada según el frente tecnológico que se trate), por ello es que la regulación, entendida como el estímulo y modelamien-

\footnotetext{
${ }^{14}$ Andrew Maynard (Sin autor, 2006-A y 2006-B) sugería a principios de 2006 que los gobiernos y la industria debían incrementar su gasto en investigación sobre los peligros ambientales y a la salud de las nanotecnologías pues entonces de un total de 9 mil millones de dólares de gasto total anual, sólo se destinaban a ese rubro entre 15 y 40 millones de dólares. Datos de Rejeski (2005) vertidos ante la Cámara de Representantes de EUA hablaban de un monto de unos 23 millones de dólares en más de 150 proyectos en medioambiente, salud y seguridad de las nanotecnologías en 8 agencias distintas en EUA, Canadá y la Unión Europea. También en relativo acuerdo con los datos de Maynard y Rejeski, la EPA (2005) confirmaba que desde 2001 hasta el 2005 había financiado 39 proyectos para el desarrollo de nanotecnologías de prevención de polución por un monto de 11 millones de dólares y 32 más para indagar en los potenciales impactos e implicaciones por una cifra de 10 millones. Esto sugiere que en 5 años la EPA ha destinado en promedio poco más de 4 millones de dólares anuales, de los cuales sólo 2 eran específicamente para potenciales peligros. Datos de la Iniciativa Nacional de Nanotecnología de EUA <www.nano.gov/node/19> precisan que ese tipo de gasto aumentó de 35 millones de dólares en 2005 a unos 117 millones en 2011, acumulando así más de 480 millones de dólares. Esto debe compararse con el acumulado de gasto total de ese país de poco más de 10 mil millones de dólares para el mismo periodo.
} 
FIGURA 3. Modelo normativo para la gestión y distribución del riego en la nanobiomedicina

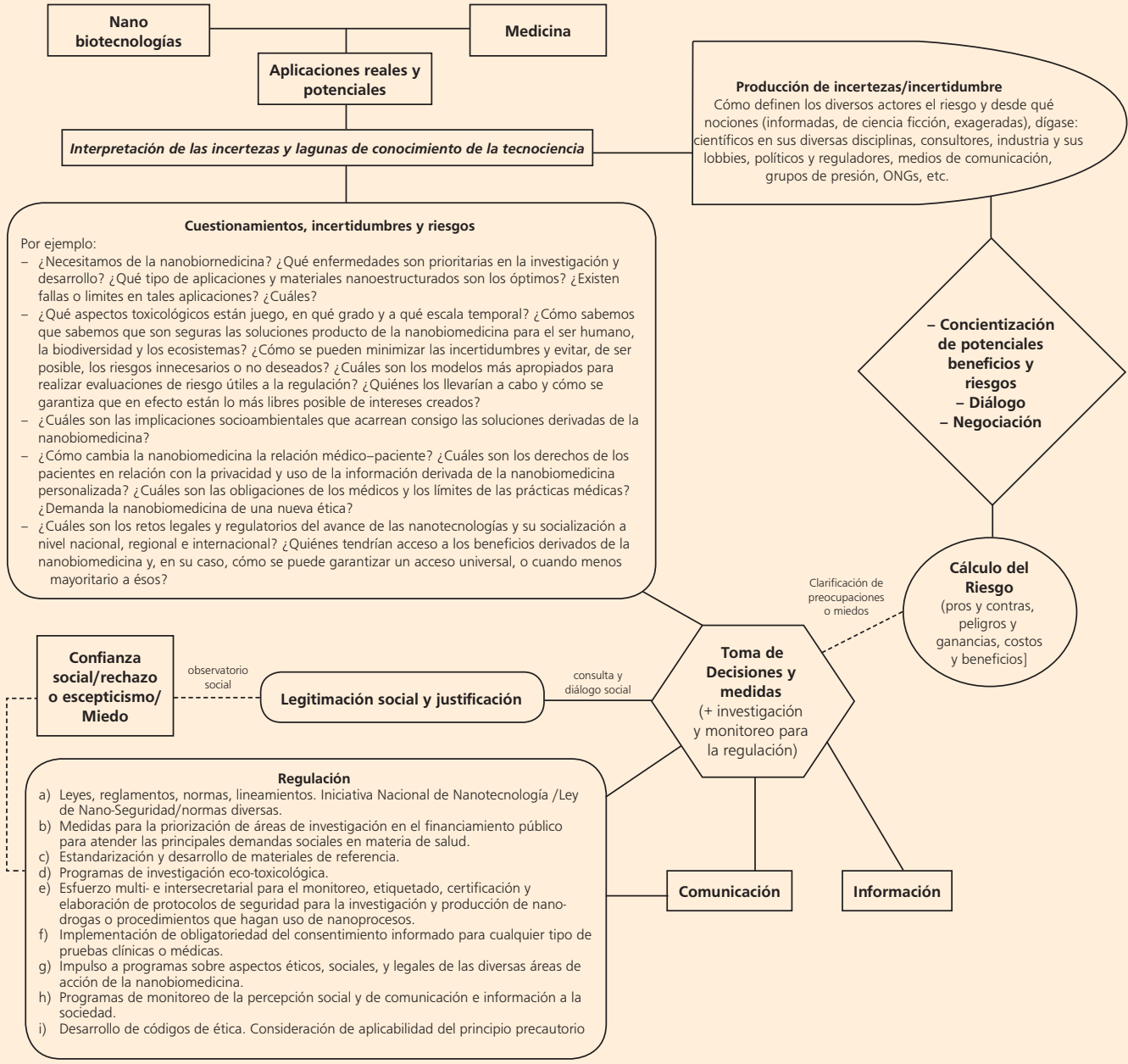

Fuente: Actualizado y modificado de Delgado, 2007.

to del avance tecnocientífico, debe ser cuidadosa, dialogada y socialmente consensuada (de tal suerte que se busque socializar tanto costos como beneficios).

En México se han adoptado por parte del Gobierno Federal, aunque de manera no vinculante, los "Lineamientos para regulaciones sobre nanotecnologías para impulsar la competitividad y proteger al medio ambiente, la salud y la seguridad de los consumidores" (Sin autor, 2012). Se trata de una acción que en sí representa ya un avance; no obstante, sigue siendo necesario otorgar a tales lineamientos efectivas capacidades regulatorias por medio del desarrollo de estándares, normas, reglamentos o inclusive de leyes. Dígase tanto para una eventual Iniciativa Nacional de Nanotecnología, como de una Ley de "NanoSeguridad". 
El camino por recorrer en el país como en otras latitudes de América Latina es enorme, tanto en materia de regulación como de planeación, estímulo y financiamiento de la ciencia y la tecnología en general(Delgado, 2012); mientras tanto, los avances (e implicaciones) de las nanociencias y la nanotecnología a nivel mundial prosigue a ritmos agigantados.

\section{REFLEXIÓn FINAL}

Consideramos que el rechazo total y en bloque de los avances científicos y tecnológicos, así como la pretensión de que cualquier cosa es válida ("todo sea por la ciencia y para la ciencia") son nociones indeseables, tanto por los potenciales riesgos y posibles implicaciones negativas, como por la exclusión, sin más, de posibles soluciones a problemáticas reales y en ciertos casos apremiantes.

La ausencia de regulación o la "autorregulación" (como se ha llegado a proponer para la nanotecnología: Roco, 2006) han demostrado en otros frentes tecnológicos su poca funcionalidad, anteponiéndose no pocas veces criterios económicos a cualquier consideración ética, social o ambiental (Delgado, 2008; EEA, 2001 y 2013). Interesa, por tanto, que en lugar de que los intereses creados y las malas prácticas pongan al ser humano al servicio de la ciencia y la tecnología, éstas en cambio estén, en los hechos y constitutivamente, al servicio del bien común de la humanidad y del entorno natural del cual ésa depende.

En el proceso, las percepciones públicas y los balances sociales a cerca de los beneficios, costos y posibles riesgos tienen un desempeño clave, de ahí que resulte imprescindible que sean comunicados transparente, completa y sistemáticamente y de cara a otras soluciones existentes (en su caso). La nanomedicina, ciertamente, no es ajena a dichas demandas más allá de sus particularidades en términos de retos, prácticas y códigos éticos, formas de gestión y de regulación.

\section{REFERENCIAS BIBLIOGRÁFICAS}

Allard, Emilie, Passirani, Catherine, y Benoit, Jean-Pierre (2009) “Convection-enhanced delivery of nanocarriers for the treatmentof brain tumors". Biomaterials, vol. 30: 23022318. DOI: $10.1016 /$ j.biomaterials.2009.01.003

Álvarez-Lemus, M., y López-Goerne, T. (2012) “Nanotecnología y cáncer: aplicación al tratamiento de tumores cerebrales". Archivos de Neurociencias, vol. 17, núm. 2, abriljunio: $102-10$.

Arnaldi, Simone., Delgado, Gian Carlo., Piccinni, Mariassunta., Poletti, Piera. (eds.) (2011) Nanomedicina. Entre políticas públicas y necesidades privadas. CEIICH, UNAM/CIGA, Universidad de Padua. México.

Arvidsson, Rickard (2012) Contributions to Emission, Exposure and Risk Assessment of Nanomaterials. Chalmers University of Technology. Gothenburg, Suecia.

Bachand, G., Allen, A., Bachand, M., Achyuthan, K., Seagrave, J., Brozik, S (2012) “Cytotoxicity and inflammation in human alveolar epithelial cells following exposure to occupational levels of gold and silver nanoparticles". Journal of Nanoparticle Research, vol. 14: 1212 . 
Bawa, Raj y Johnson, Summer (2007) "The ethical dimensions of nanomedicine”. The Medical Clinics, núm. 91. Elsevier. EUA.

BCC Research. (2012-A) Nanotechnology: A realistic market assessment. EUA.

BCC Research. (2012-B) Nanotechnology in medical applications: The global market. EUA.

BCC Research. (2013) Nanomaterials in theranostics: Global markets. EUA.

Burger PC y Green SB (1987) "Patient age, histologic features, and length of survival in patients with glioblastoma multiforme."Cancer, vol. 59: 1617-25.

CDRSEHSAEN - Committee to Develop a Research Strategy for Environmental, Health, and Safety Aspects of Engineered Nanomaterials (2012) A research strategy for environmental, health and safety aspects of engineered nanomaterials. National Research Council. National Academies. Washington, D.C., EUA.

De Cozar Escalante, José Manuel (2010) Nanotecnología, salud y bioética (entre la esperanza y el riesgo). Junta General del Principado de Asturias (JGPA), Sociedad Internacional de Bioética. España. <http://jcozar.webs.ull.es/files/libro_premio_jgpa_sibi_2010. pdf>.

Delgado Ramos, Gian Carlo (2007) Incertidumbres de la nanotecnología y su manejo social, tesis doctoral. Instituto de Ciencia y Tecnología Ambiental. Universidad Autónoma de Barcelona. España.

Delgado Ramos, Gian Carlo (2008) Guerra por lo invisible: negocio, implicaciones y riesgos de la nanotecnología, Colección El Mundo Actual, CEIICH-UNAM. México.

Delgado Ramos, Gian Carlo (2012) “Ciencia y tecnología en América Latina: balance y perspectivas”. Tecnura, vol. 16, núm. especial. Facultad Tecnológica, Universidad Distrital Francisco José de Caldas. Bogotá, Colombia.

Delgado-Ramos, Gian Carlo (2013) “Ethical, social, environmental and legal aspects of nanotechnologies: A reading from Mexico". International Journal of Innovation and Technology Management, vol. 10, núm. 2: 130001-1 a 130001-23.

De Rijk, M.C.; Launer, L.J;; Berger, K.; Breteler, M.M.; Dartigues, J.F.; Baldereschi, M.; Fratiglioni, L.; Lobo, A.; Martinez-Lage, J.; Trenkwalder, C. y Hofman, A. (2000) "Prevalence of Parkinson's disease in Europe: A collaborative study of population-based cohorts." Neurology, vol. 54, núm. 11: S21- S23.

EEA-European Environment Agency (2001) Late lessons from early warnings: The precautionary prnciple 1896-2000. Unión Europea. Copenague, Dinamarca

EEA-European Environment Agency (2013) Late lessons from early warnings: Science, precaution, innovation. Unión Europea. Copenague, Dinamarca.

Electronics (2010) Nanotechnology: A realistic market assessment. Electronics Industry Market Research and Knowledge Network. Canada, 2010.

Electronics (2012) World nanomaterials. Electronics Industry Market Research and Knowledge Network. Canada, Mayo.

EPA-Environmental Protection Agency (2005) Nanotechnology white paper. EPA's Science Policy Council. EUA, 2 de diciembre.

ESF (2005) ESF forward look on nanomedicine. European Science Foundation. Noviembre. <http://www.esf.org/publication/214/Nanomedicine.pdf>.

Freedonia Group (2007) Report: Nanotechnology in healthcare. Ohio, EUA.

Funtowicz, Silvio y Ravetz, Jerome (1990) Uncertainty and quality in science policy. Kluwer Academic. Londres, Reino Unido. 
Funtowicz, Silvio y Strand, Roger (2007) “De la demostración experta al diálogo participativo". Revista CTS, núm. 8, vol. 3, abril: $97-113$.

Global Industry Analysts (2012) Nanotechnology. A global industry outlook. EMR Reports. Corea del Sur.

Hickey, Hannah (2009) "Nanoparticles cross blood-brain barrier to enable 'brain tumor painting'". News and Information. Universidad de Washington. 3 de agosto. <www. washington.edu/news/2009/08/03/nanoparticles-cross-blood-brain-barrier-toenable-brain-tumor-painting/>.

ISO-International Standardization Organization (2008) Health and safety practices in occupational settings relevant to nanotechnologies. ISO/TR 12885. Suiza.

ISO-International Standardization Organization (2010) Guidance on the labelling of manufactured nano-objects and products containing manufactured nan-objects. Draft Technical Specification. ISO/DTS. 13830. Suiza.

Jain K, Jain V (2006) "Impact of nanotechnology on healthcare-applications in cell therapy and tissue engineering." Nanotechnology Law Business, vol. 3, núm. 4: 411-418.

Jastrzebska, A.; Kurtycz, P. y Olszyna, A. (2012) "Recent advances in grapheme family materials toxicity invetigations". Journal of Nanoparticle Research, vol. 14: 1320.

Jotterand, F., y Alexander, A.A. (2011) “Managing the 'known unknowns': theranostic cáncer nanomedicine and informed consent". Methods in Molecular Biolog, 413-429. DOI: 10.1007/978-1-61779-052-2_26.

Kievit, Forrest y Zhang, Miqin (2011) “Cancer nanotheranostics: Improving imaging and therapy by targeted delivery across biological barriers." Advanced Materials, vol. 23, núm. 36: H217-H247. DOI: 10.1002/adma.201102313.

Lin, W., Yi, X., Huang, C., Ma, Y., Shannon, K., Chen, D. y Huang, Y. (2009) “Toxicity of nanoand micro-sized ZnO particles in human lung epithelial cells". Journal of Nanoparticle Research, vol. 11, núm. 1: 25-39.

Loch-Neckel, Gecioni y Koepp, Janice (2010) "La barrera hematoencefálica y la administración de medicamentos en el sistema nervioso central”. Revista de Neurología, vol. 51, núm. 3: 165-174.

Loera Serna, Sandra.; Ruíz Ángeles, Jazmín.; Flores Moreno, Jorge y Soto Portas, Lídice (2012) "Protegiendo fármacos con nanomateriales inteligentes." Mundo Nano. Revista Interdisciplinaria en Nanociencias y Nanotecnología, vol. 5, núm. 1, nanoUNAM. México, enero-junio: 59-68.

López-Goerne T.; Ortiz E.; Quintana P. y González, R.D. (2007) “A nanostructured titania bioceramic implantable device capable of drug delivery to the temporal lobe of the brain". Colloids and Surfaces A: Physicochemical and Engineering Aspects, vol. 300, núms. 1 y 2: 3-10.

López-Goerne, T.; Recillas, S.; Guevara, P.; Sotelo, J.; Álvarez, M. y Odriozola, J.A. (2008) “Pt/ TiO2 brain biocompatible nanoparticles: GBM treatment using the $\mathrm{C} 6$ model in Wistar rats". Acta Biomaterialia, vol. 4: 2037-2044.

López-Goerne T.; Figueras F.; Manjarrez J.; Bustos, J.; Álvarez, M. y Silvestre-Albero, J. (2010) "Catalytic nanomedicine: a new field in antitumor treatment using supported platinum nanoparticles. In vitro DNA degradation and in vivo tests with C6 animal model on Wistar rats". European Journal of Medicinal Chemestry, vol. 45: 1982-1990. 
López-Goerne, Tessy; Ortíz Islas, Emma; Álvarez, Mayra y Donald, Richard (2011) “Nanostructured $\mathrm{Pt}\left(\mathrm{NH}_{3}\right)_{4} \mathrm{Cl}_{2} / \mathrm{SiO}_{2}$ for nanomedicine: catalytic degradation of DNA in cáncer cells". Nano Reviews, vol. 2: 5461. DOI: 10.3402/nano.v2i0.5461.

Lovern, Sarah B. y Klaper, Rebecca (2006) "Daphinia Magna Mortality When Exposed to Totanium Dioxide and Fullerene (C60) Nanoparticles". Environmental Toxicology and Chemistry, vol. 25, núm. 4: 1132-1137.

Lupton, M. (2011) “The social, moral \& ethical issues raised by nanotechnology in the field of medicine”. Medical Law, vol. 30, núm. 2: 187-200.

Maynard, Andrew (2006) Nanotechnology: A research strategy for addressing Risk. EUA,Woodrow Wilson International Centre for Scholars.

Mikkelsen, S., Hansen, E. y Christensen, T.B. (2011) Survey on basic knowledge about exposure and potential environmental and health risks for selected Nanomaterials. Danish Ministry of the Environment. Environmental Protection Agency. Proyecto No. 1370 2011. Dinamarca.

Murashov, V. (2009) "Occupational exposure to nanomedical applications." Wiley Interdisciplinary Reviews. Nanomedicine and Nanobiotechnology, vol. 1, núm. 2: 203-213. DOI: 10.1002/wnan.31.

Nanospots (2007) Government Policy and Initiatives in Nanotechnology Worldwide 2007. Canadá, Nanospots.

NanotechNow (sin fecha) "Nano-enabled drug delivery market to pass US\$1.7 billion in 2009 NanoMarkets”. <www.nanotech-now.com/ news.cgi?story_id=08590>.

National Cancer Institute (2005) Nanotechnology Tackles Brain Cancer. NCI Alliance for Nanotechnology in Cancer. Diciembre. <http://nano.cancer.gov/action/news/featurestories/monthly_feature_2005_dec.pdf>.

Nazarenko, Y.; Zhen, H.; Han, T.; Lioy, P. y Mainelis, G. (2012) "Nanomaterial inhalation exposure from nanotechnology-based cosmetic powders: a quantitative assessment". Journal of Nanoparticle Research, vol. 14: 1229.

NSF (2010) Science \& Engineering Indicators 2010. National Science Board. EUA.

Oberdorster, G.; Sharp, Z.; Atudorei, V.; Elder, A.; Gelein, R.; Kreyling, W. y Cox, C. (2004) "Translocation of inhaled ultrafine particles to the brain." Inhalation Toxicology, núm. 16: 437-445.

Oberdorster, G.; Sharp, Z.; Atudorei, V.; Elder, A.; Gelein, R.; Lunts, A. et al. (2002) “Extrapulmonary translocation of ultrafine carbon particles following whole-body inhalation exposure of rats." Journal of Toxicology and Environmental Health. A 65 EUA: 15311543.

Peralta, Leonardo (2012) "La nanomedicina produce 'milagros' en pacientes con cáncer". CNN México. <http://mexico.cnn.com/salud/2012/01/29/la-nanomedicina-produce-milagros-en-pacientes-con-cancer>.

Poland, Craig et al (2008) "Carbon nanotubes introduced into the abdominal cavity of mice show asbestos-like pathogenicity in a pilot study." Nature Nanotechnology, vol. 3: 423-428.

Re, Francesca.; Gregori, Maria y Masserini, Massimo (2012) "Nanotechnology for neurodegenerative disorders”. Nanomedicine: Nanotechnology, Biology and Medicine, vol. 8. Supplement 1: S51-S58. DOI: 10.1016/j.nano.2012.05.007. 
Rejeski, David (2005) "Environmental and safety impacts of nanotechnology: What research is needed?". Pronunciamiento ante el Comité de Ciencia de la Casa de Representantes. EUA, 17 de noviembre.

Renn, Ortwin y Roco, Mihail (2006) "Nanotechnology and the need for risk governance". Journal of Nanoparticle Research, vol. 8 (2-3). Springer Science.

Research Markets (2013) Nanotechnology market outlook 2017. Reserach Markets. Dublín, Irlanda.

Roco, Mihail (2006) "Progress in gobernance of converging technologies integrated from nanoscales". Annals of the New York Academy of Science, vol. 1093. EUA: 1-23.

Roco, Mihail; Mirkin, Chad y Hersam, Mark (2010). Nanotechnology research directions forsocietal needs in 2020. EUA: Springer.

Rozhkova, Elena (2011) “Nanoscale materials for tackling brain cancer: Recent progress and outlook". Advanced Materials, vol. 23, núm. 24, junio: H136-H150. COI: 10.1002/ adma.201004714.

Sanhai et al. (2008) “Seven challenges for nanomedicine”. Nature Nanotech, núm. 3: 242244.

Sharma, M. (2010) "Understanding the mechanism of toxicity of carbon nanoparticles in humans in the new millennium: A systemic review". Indian Journal of Occupational and Environmental Medicine, vol. 14, núm. 1: 3-5. DOI: 10.4103/0019-5278.64607.

Sharma, Arati; Madhunapantula, SubbaRao y Robertson, Gavin (2012) "Tosicological considerations when creating nanoparticle based drugs and drug delivery systems?". Expert Opinion on Drug Metabolism \& Toxiciology, vol. 8, núm. 1: 47-69. DOI: $101517 / 17425255.2012 .637916$.

Sin autor (2006-A) "Nanodollars". New Scientist. EUA.

Sin autor (2006-B) "Nano safety call”. New Scientist. EUA.

Sin Autor (2012) "Lineamientos para regulaciones sobre nanotecnologías para impulsar la competitividad y proteger el medio ambiente, la salud y la seguridad de los consumidores".Mundo Nano. Revista Interdisciplinaria en Nanociencia y Nanotecnologia, vol. 5, núm. 9, nanoUNAM. México, julio-diciembre: 13-16.

Shatkin, Jo Anne (2008) Nanotechnology health and environmental risks. CRC Press. EUA.

Song, Y.; Li, X. y Du, X. (2009) "Exposure to nanoparticles is related to pleural effusion, pulmonary fibrosis and granuloma”. European Respiratory Journal, vol. 34: 559-567.

Strand, Roger y Nydal, Rune (2008) "Nanoética buena-nanotecnología buena". Mundo Nano. Revista Interdisciplinaria en Nanociencia y Nanotecnología, vol. 1, núm. 1, nanoUNAM. México, julio-diciembre: 61-79.

Tsuda, H.; Xu, J.; Sakai, Y.; Futakuchi, M. y Fukamachi, K. (2009) “Toxicology of engineered nanomaterials-a review of carcinogenic potential". Asian Pacific Journal on Cancer Prevention, vol. 10, núm. 6: 975-980.

Wagner, Volker y Zweck, Axel (2006) "The emerging nanomedicine landscape". Nature Biotechnology, vol. 24, núm. 10, octubre. EUA.

Webser, P. (2005). "World nanobiotechnology market". Nanomedicine, vol. 1, núm. 2. Frost \& Sullivan: 140-142.

Wickson, Fen (2011) “Gobernanza nanotecnológica: por qué no podemos confiar en evaluaciones científicas de riesgo." Mundo Nano. Revista Interdisciplinaria en Nanociencia y Nanotecnología, vol. 3, núm. 2. México, julio-diciembre. 
Yang, L., y Watts, D.J. (2005). "Particle surface characteristics may play an important role in phytotoxicity of alumina nanoparticles”. Toxicology Letters, núm. 158: 122-132.

Yoshioba, Y.; Yoshikawa, T. y Tsutsumi, Y. (2010) "Nano-safety science for assuring the safty of nanomaterials”. Nihon Eiseigaku Zasshi, vol. 65, núm. 4: 487-492.

Zhang, L.; Alizadeh, D. y Badie, B. (2010) "Carbon nanotube uptake and toxicity in the brain". Methods in Molecular Biology, vol. 625: 55-65. DOI: 10.1007/978-1-60761-5798_6. 